\title{
Computational Study of the Formation Reaction of Polyacid Precursors of Glass-Ionomer Materials
}

\author{
Jair Gaviria', Jairo Quijano1, Pablo Ruiz ${ }^{1,2}$ \\ ${ }^{1}$ Facultad de Ciencias, Universidad Nacional de Colombia, Medellín, Colombia \\ ${ }^{2}$ Facultad de Ciencias Exactas y Aplicadas, Instituto Tecnológico Metropolitano, Medellín, Colombia \\ Email: jgarango@unal.edu.co,jquijano@unal.edu.co,paruizr@unal.edu.co
}

How to cite this paper: Gaviria, J., Quijano, J. and Ruiz, P. (2021) Computational Study of the Formation Reaction of Polyacid Precursors of Glass-Ionomer Materials. Journal of Materials Science and Chemical Engineering, 9, 1-9.

https://doi.org/10.4236/msce.2021.98001

Received: July 10, 2021

Accepted: August 3, 2021

Published: August 6, 2021

Copyright $\odot 2021$ by author(s) and Scientific Research Publishing Inc. This work is licensed under the Creative Commons Attribution International License (CC BY 4.0).

http://creativecommons.org/licenses/by/4.0/

\begin{abstract}
The formation of polyacids in a glass-ionomer cement was computationally modeled. The polyacid modelled is an oligomer made up of three molecules: acrylic acid, itaconic acid and an additional molecule that acts as a spacer group between the previous two. Acryloyl and meta-acryloyl derivatives of some amino acids and related molecules such as $\mathrm{N}$-vinyl pyrrolidone and $\mathrm{N}$ vinyl caprolactam were used as spacer groups. Some of these molecules have been previously used experimentally as spacer groups. In this work the spacer behaviour of 15 different molecules was investigated. To our knowledge, this is the first computational attempt to model some promising molecules to be incorporated into glass-ionomer dental cements. The results revealed the best structural arrangement for the investigated molecules.
\end{abstract}

\section{Keywords}

Cements, Glass Ionomer, Polyacids, Spacers, Terpolymers

\section{Introduction}

Cements in dentistry (glass-ionomer) are composite materials based on mixtures of a solid and a liquid that, through an acid-base reaction, produce a solid matrix [1] [2]. There are two uses for these materials: To fill a gap in a tooth, that is, as a restorative material, and to hold in place a manufactured device, such as an orthodontic bracket or crown.

Conventional glass ionomer cements (GIC) have the following components: glass powder (a fluoroaluminosilicate glass degradable by a specifically formulated acid); acid (homopolymer of acrylic acid or a related copolymer); tartaric acid (+), 
(improves the performance and speeds up the setting time) and water (acts as the reaction medium) [3] [4].

The acids used in the conventional glass ionomer system are polyelectrolytes which are water-soluble polymers and electrolytes. The polyelectrolytes used in GIC are polyalkenoic. These polyacids include the homopolymers and copolymers of unsaturated mono, di, and tricarboxylic acids.

To improve the mechanical properties of GICs, researchers have explored modifications of the liquid component of GIC to increase crosslinking between polymer chains during the hardening reaction. Modifications of the GIC liquid include the formation of new polyacids, and the introduction of copolymers of acrylic, itaconic [5] [6] [7] [8], or maleic acids [7]-[13], containing flexible side chains of amino acids [14] [15] [16] [17], N-vinyl pyrrolidone [18]-[23] or N-vinylcaprolactam [17] [24].

Crisp and Wilson [8] suggested that copolymers of acrylic acid with other unsaturated carboxylic acids (itaconic and maleic acid) would reduce intermolecular hydrogen bonds due to their reduced stereoregularity compared to homopolymers of acrylic acid, the reduction of intermolecular hydrogen bonds observed in these copolymers is attributed to the higher degree of cross-linking due to the presence of two carboxyl groups in the structure of the co-polymer.

Polyacids are generally prepared by free radical polymerization of the appropriate monomers in aqueous solution, in the presence of a chain transfer agent and an initiator such as ammonium persulfate. These polyacids consist of straight chains without crosslinking, but have excess acid groups [25].

This study investigated the thermodynamic stability of the polyacids obtained from the different combinations between acrylic acid, itaconic acid and a spacer group. Each spacer group has 3 different possibilities of being combined with the respective acids for which, a total of 45 polyacid molecules were studied. For modeling purposes, only a single basic structural unit of the polymer was taken into account. Of the selected spacers there are some molecules with terminal vinyl groups that can react directly with acids and do not require derivation with acryloyl or methacryloyl chloride, such as $\mathrm{N}$-vinylcaprolactam, $\mathrm{N}$-vinylpyrrolidone and eugenol. The other molecules are forced to acquire the vinyl bond, like in the reaction of $\beta$-alanine with acryloyl chloride to form acryloyl $\beta$-alanine (ABA) as shown in Figure 1.

\section{Computational Methodology}

The polyacids studied were formed by the combination of acrylic acid, itaconic

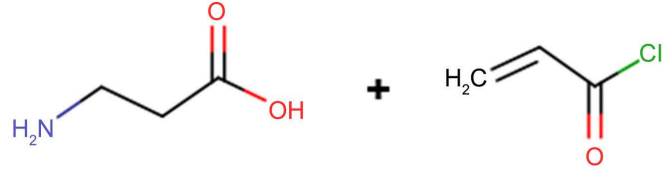

acryloyl cloride

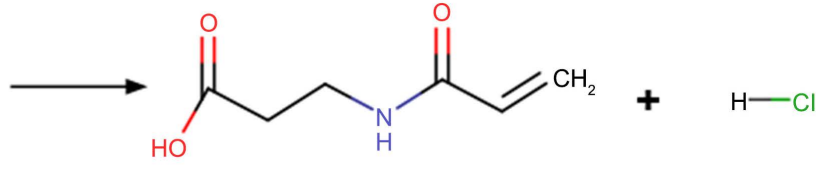

acryloyl beta-alanine

Figure 1. Derivatization of $\beta$-alanine. 
acid and a spacer. They were modeled with the Spartan 14 software [26] so that each of the asymmetric carbons of the molecules had the R configuration. Subsequently, conformational analysis calculations were performed to select the most stable conformer of each structure. The termination step in the radical reaction for the formation of polyacids was simulated with a methyl radical.

All molecules were fully optimized with the Gaussian 09 computational package [27] using the density functional theory (DFT). Previous optimization calculations for the molecules in gas phase were made for comparative purposes, using two different functionals: B3LYP [28] and M06-2X [29]. The results obtained with the M06-2X functional allowed a higher resolution of the energies. This functional is recommended for thermochemistry applications [29].

The calculations in aqueous solution were performed using the polarizable continuous model with the integral equation formalism (IEFPCM) [30]. The functional M06-2X and basis set 6-311G(d, p) were used [31]. The optimization was carried out at $333.15 \mathrm{~K}$ and $1 \mathrm{~atm}$.

Vibrational frequency calculations were performed to obtain the thermodynamic parameters of the molecules studied. The enthalpy and entropy values were evaluated according to standard thermodynamic equations [32].

\section{Results and Discussion}

The union between the amino acid derivative, acrylic acid $\left(\mathrm{C}_{3} \mathrm{H}_{4} \mathrm{O}_{2}\right)$ and itaconic acid $\left(\mathrm{C}_{5} \mathrm{H}_{6} \mathrm{O}_{4}\right)$, occurs through radical reactions. For modeling purposes, the terminal step was carried out with two methyl radicals. The structures of 15 molecules used as spacers are represented in Figure 2, where 1) N-acryloyl-6-aminocaproic

1

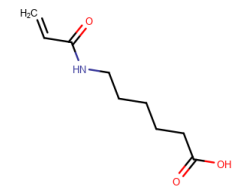

6

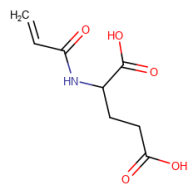

11

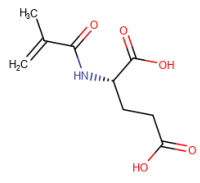

2<smiles>C/C=C\C(=O)NC(Cc1ccccc1)C(=O)O</smiles>

7<smiles>C=CC(=O)NC(Cc1c[nH]cn1)C(=O)O</smiles>

12

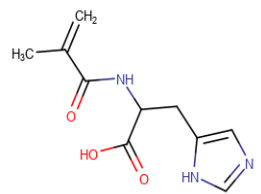

3<smiles>O=C(O)/C=C\C(=O)NC(Cc1ccc(Cl)cc1)C(=O)O</smiles>

8<smiles>C=CCc1ccc(O)c(OC)c1</smiles>

13

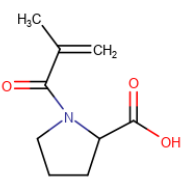

4<smiles>C=CC(=O)NCCC(=O)O</smiles>

9

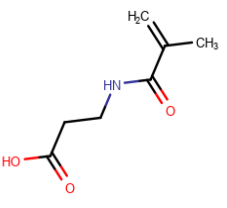

14

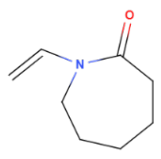

5<smiles>O=CC(=O)NCC(=O)O</smiles>

10<smiles>C=C(C)C(=O)NCC(=O)O</smiles>

15

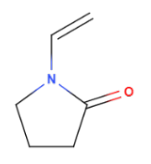

Figure 2. Structure of the molecules used as spacers. 
acid (AACA), 2) molecule derived from phenylalanine (AADH), 3) molecule derived from tyrosine (AADOH), 4) acryloyl $\beta$-alanine (ABA), 5) acryloyl glycine (AG), 6) acryloyl glutamic acid (AGA), 7) acryloyl histidine (AH), 8) eugenol (EU), 9) methacryloyl $\beta$-alanine (MBA), 10) methacryloyl glycine (MG), 11) methacryloyl glutamic acid (MGA), 12) methacryloyl histidine (MH), 13) N-methacryloyl proline (NMP), 14) N-vinylcaprolactam (NVC), 15) N-vinylpyrrolidone (NVP).

Figure 3 displays an example of the different structural configurations that can be obtained by combining methacryloyl beta alanine with acrylic and itaconic acids (MBA-AA-IA, AA-MBA-IA and AA-IA-MBA; from now on MBA-1, MBA2 and MBA-3 respectively, the same nomenclature is adopted for the rest of the molecules obtained from the different spacers. These combinations were modeled for each amino acid derivative used, for a total of 45 molecules that were optimized in the Gaussian 09 computational package to M06-2X/6-311G(d, p). The geometric structures optimized for the MBA polyacid example are shown in Figure 4 .
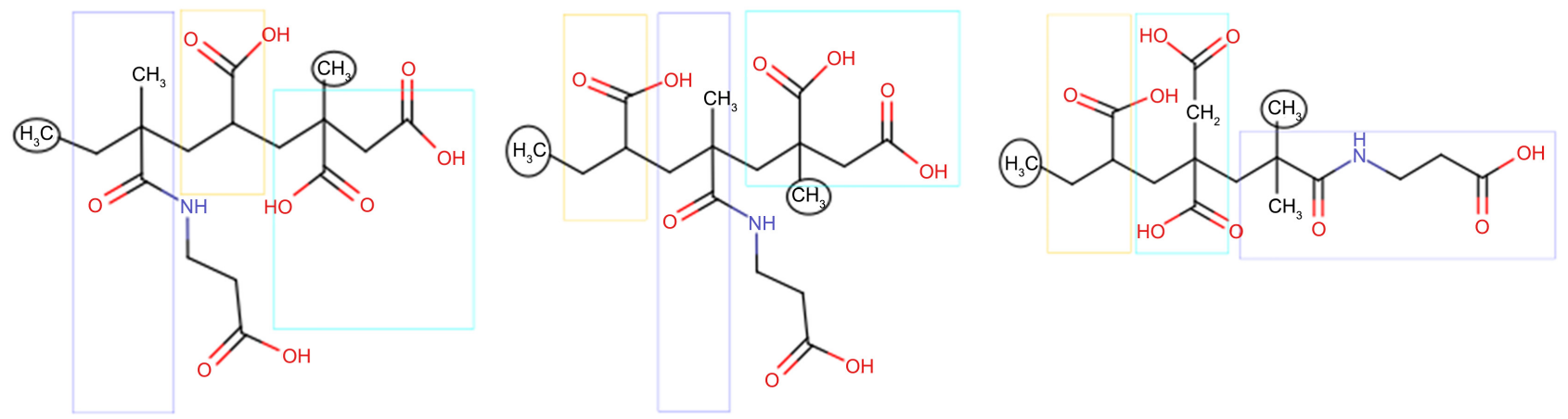

Figure 3. MBA-1, MBA-2 and MBA-3. From left to right, MBA is in positions 1, 2 and 3, respectively.

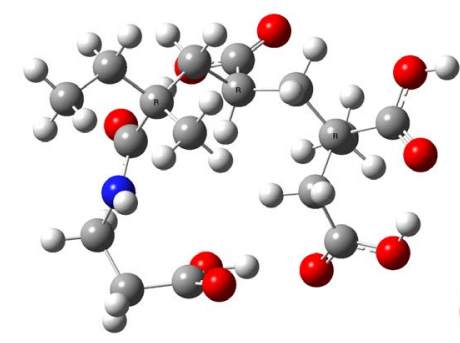

(a)

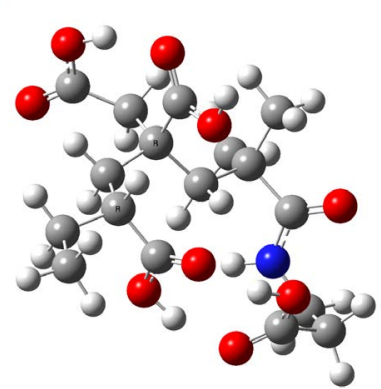

(c)

Figure 4. Geometric structures of the polyacid, optimized to M06-2X/6-311G(d, p) in aqueous solution. (a) MBA-1; (b) MBA-2; (c) MBA-3. 
The results from the optimization process are presented in Table $1 . \Delta \mathrm{G}$ is the relative energy (Gibbs energy of each spacer subtracting the value of the same type of spacer with lower energy).

From the results of the Gibbs energy of each molecule, the best combinations obtained in terms of energy stability $(\triangle \mathrm{G}=0$ ) were the following: AACA-1, AADH1, AADOH-3, ABA-1, AG-1, AGA-2, AH-2, EU-2, MBA-1, MG-1, MGA-1, MH1, NMP-1, NVC-1, and NVP-1.

It is determined that $80 \%$ of the molecules studied have greater energy stability when the spacer is at one end. Also $93.3 \%$ of the molecules are more stable if itaconic acid is at one end or acrylic acid is in the middle.

In the structure of the optimized polyacid molecules, it is possible to observe the way in which the atoms are grouped for the different combinations between spacer, AA and IA. There are approaches between oxygen and nitrogen atoms with hydrogen atoms, which presupposes the formation of hydrogen bonding. This generates energy stabilization, although an entropic loss occurs. Finally, the stability of the molecule will be given by an energy balance between the different interactions of the atoms in modeled molecule. The spacer and itaconic acid structures (which has two $\mathrm{COOH}$ groups) are likely to increase atomic repulsions when in the center of the structure.

Single point calculations were performed for the most stable molecules using Spartan 14 computational package with the CPK method (space-filling model) [33]. The area of each structure was determined in order to find a possible correlation of that property with the energy of the molecule. The results are shown in Table 2.

Table 1. Relative Gibbs energy, $\Delta \mathrm{G}(\mathrm{kJ} / \mathrm{mol})$ from the data obtained from the optimization of the molecules, for the combinations of spacer, itaconic acid and acrylic acid.

\begin{tabular}{cccccc}
\hline Molecule & $\Delta \mathrm{G}$ & Molecule & $\Delta \mathrm{G}$ & Molecule & $\Delta \mathrm{G}$ \\
\hline AACA-1 & 0.0 & AGA-1 & 23.1 & MGA-1 & 0.0 \\
AACA-2 & 8.6 & AGA-2 & 0.0 & MGA-2 & 20.7 \\
AACA-3 & 12.8 & AGA-3 & 10.5 & MGA-3 & 1.5 \\
AADH-1 & 0.0 & AH-1 & 2.0 & MH-1 & 0.0 \\
AADH-2 & 47.8 & AH-2 & 0.0 & MH-2 & 14.5 \\
AADH-3 & 13.7 & AH-3 & 38.4 & MH-3 & 9.2 \\
AADOH-1 & 27.6 & EU-1 & 0.65 & NMP-1 & 0.0 \\
AADOH-2 & 22.6 & EU-2 & 0.0 & NMP-2 & 18.0 \\
AADOH-3 & 0.0 & EU-3 & 12.7 & NMP-3 & 14.9 \\
ABA-1 & 0.0 & MBA-1 & 0.0 & NVC-1 & 0.0 \\
ABA-2 & 12.6 & MBA-2 & 35.6 & ANVC-2 & 4.6 \\
ABA-3 & 16.7 & MBA-3 & 20.2 & NVC-3 & 14.1 \\
AG-1 & 0.0 & MG-1 & 0.0 & NVP-1 & 0.0 \\
AG-2 & 1.1 & MG-2 & 5.5 & NVP-2 & 10.8 \\
AG-3 & 16.5 & MG-3 & 46.6 & NVP-3 & 34.8 \\
\hline
\end{tabular}


Table 2. Area of the most stable structures of the polyacids studied. Obtained with the CPK method.

\begin{tabular}{cccccc}
\hline Molecule & Area $(\AA 2)$ & Molecule & Area $(\AA 2)$ & Molecule & Area $(\AA 2)$ \\
\hline AACA-1 & 417.60 & AGA-1 & 416.64 & MGA-1 & 422.68 \\
AACA-2 & 418.97 & AGA-2 & 409.35 & MGA-2 & 408.33 \\
AACA-3 & 421.95 & AGA-3 & 391.87 & MGA-3 & 415.57 \\
AADH-1 & 446.65 & AH-1 & 433.38 & MH-1 & 437.95 \\
AADH-2 & 436.58 & AH-2 & 420.53 & MH-2 & 425.82 \\
AADH-3 & 440.12 & AH-3 & 427.46 & MH-3 & 437.63 \\
AADOH-1 & 444.29 & EU-1 & 397.39 & NMP-1 & 394.63 \\
AADOH-2 & 432.72 & EU-2 & 407.36 & NMP-2 & 398.59 \\
AADOH-3 & 438.50 & EU-3 & 400.41 & NMP-3 & 393.54 \\
ABA-1 & 364.52 & MBA-1 & 379.63 & NVC-1 & 377.27 \\
ABA-2 & 368.96 & MBA-2 & 371.68 & NVC-2 & 374.81 \\
ABA-3 & 366.79 & MBA-3 & 376.36 & NVC-3 & 379.01 \\
AG-1 & 348.80 & MG-1 & 365.14 & NVP-1 & 336.39 \\
AG-2 & 355.82 & MG-2 & 361.40 & NVP-2 & 341.05 \\
AG-3 & 353.45 & MG-3 & 362.53 & NVP-3 & 336.20 \\
\hline
\end{tabular}

The results show that for 6 different spacers, the combinations with the lowest energy also have the largest area in their molecules. This is the case of AADH, EU, MBA, MG, MGA and MH. In contrast, the spacers AACA, ABA, AG and $\mathrm{AH}$ have a smaller molecular area for the most stable combination with AA and IA.

It is not possible to make a generalization regarding a possible correlation between the areas of the molecules and their energetic stability. Each molecule studied is a particular case where there may or may not be favorable interactions between the spacer and the acids.

In conclusion, the derivative of the amino acid used does not only act as a spacer of the structure for the formation of the oligomer, but it establishes important energetic interactions with IA and AA, allowing a compaction and energetic stabilization of the structure.

\section{Conclusions}

According to the optimization and energy results, most of the polyacid molecules present greater stability when the spacer is at one end: AACA-1, AADH-1, AADOH-3, ABA-1, AG-1, MBA-1, MG-1, MGA-1, MH-1, NMP-1, NVC-1, NVP1. AGA-2, AH-2 and EU-2 are excepted.

Greater stability of the optimized polyacids does not necessarily correspond to a greater surface area of the molecules.

The compaction generated by the spacer in the different polyacids formed, de- 
pends on their molecular nature and the interactions that can be generated with $\mathrm{AA}$ and IA.

\section{Acknowledgements}

The authors thank to Universidad Nacional de Colombia-Medellin for the support received for the research of this work. P.R also thanks to Instituto Tecnológico Metropolitano (ITM).

\section{Conflicts of Interest}

The authors declare no conflicts of interest regarding the publication of this paper.

\section{References}

[1] McLean, J.W., Nicholson, J.W. and Wilson, A.D. (1994) Proposed Nomenclature for Glass-Ionomer Dental Cements and Related Materials. Quintessence International, 25, 587-589.

[2] Wilson, A. (1991) Glass-Ionomer Cement Origins, Development and Future. Clinical Materials, 7, 275-282. https://doi.org/10.1016/0267-6605(91)90070-V

[3] Baig, M.S. and Fleming, G.J.P. (2015) Conventional Glass-Ionomer Materials: A Review of the Developments in Glass Powder, Polyacid Liquid and the Strategies of Reinforcement. Journal of Dentistry, 43, 897-912. https://doi.org/10.1016/j.jdent.2015.04.004

[4] Nicholson, J.W. (1998) Chemistry of Glass-Ionomer Cements: A Review. Biomaterials, 19, 485-494. https://doi.org/10.1016/S0142-9612(97)00128-2

[5] Crisp, S., Kent, B.E., Lewis, B.G., Ferner, A.J. and Wilson, A.D. (1980) Glass-Ionomer Cement Formulations. II. The Synthesis of Novel Polycarobxylic Acids. Journal of Dental Research, 59, 1055-1063. https://doi.org/10.1177\%2F00220345800590060801

[6] Wilson, A.D. and McLean, J. (1988) Composition. In: Wilson, A. and McLean, J., Eds., Glass-Ionomer Cement, Quintessence Publishing Co. Inc., Chicago, 21-42.

[7] Nicholson, J. (1997) Polyelectrolyte Restorative Materials. In: Abe, A., Monnerie, L., Shibaev, V., Suter, U.W., Tirrell, D. and Ward, M., Eds., Polymeric Dental Materials, Springer, Berlin, Heidelberg, 1-50. https://doi.org/10.1007/978-3-642-60537-6_1

[8] Crisp, S. and Wilson, A. (1977) Cements Comprising Acrylic and Itaconic Acid Copolymers and Fluoroaluminosilicate Glass Powder. US Patent No. 4016124A.

[9] Khouw-Liu, V.H.W., Anstice, H.M. and Pearson, G.J. (1999) An in Vitro Investigation of a Poly (Vinyl Phosphonic acid) Based Cement with Four Conventional GlassIonomer Cements. Part 1: Flexural Strength and Fluoride Release. Journal of Dentistry, 27, 351-357. https://doi.org/10.1016/S0300-5712(98)00061-X

[10] Williams, J. and Billington, R. (1991) Changes in Compressive Strength of Glass-Ionomer Restorative Materials with Respect to Time Periods of 24h to 4 Months. Journal of Oral Rehabilitation, 18, 163-168. https://doi.org/10.1111/j.1365-2842.1991.tb00044.x

[11] Nicholson, J.W. and Abiden, F. (1997) Changes in Compressive Strength on Ageing in Glass Polyalkenoate (Glass-Ionomer) Cements Prepared from Acrylic/Maleic Acid Copolymers. Biomaterials, 18, 59-62. 
https://doi.org/10.1016/S0142-9612(96)00109-3

[12] Pearson, G. and Atkinson, A. (1991) Long-Term Flexural Strength of Glass Ionomer Cements. Biomaterials, 12, 658-660. https://doi.org/10.1016/0142-9612(91)90113-O

[13] Schmitt, W., Purrmann, R., Jochum, P. and Gasser, O. (1982) Mixing Component for Dental Glass-Ionomer Cements. US Patent No. 4360605A

[14] Culbertson, B. and Kao, E. (1994) Water Soluble Polymers Containing Amino Acid Residues for Dental Restoratives. US Patent No. 5369142A

[15] Kao, E.C., Culbertson, B.M. and Xie, D. (1996) Preparation of Glass Ionomer Cement Using N-Acryloyl-Substituted Amino Acid Monomers-Evaluation of Physical Properties. Dental Materials, 12, 44-51. https://doi.org/10.1016/S0109-5641(96)80063-7

[16] Culbertson, B.M., Xie, D. and Thakur, A. (1999) New Matrix Resins for Glass Polyalkenoates or Glass-Ionomers with Pendant Amino Acid Residues. Journal of Macromolecular Science, Part A, 36A, 681-696. https://doi.org/10.1081/MA-100101557

[17] Moshaverinia, A., Roohpour, N., Darr, J.A. and Rehman, I.U. (2009) Synthesis and Characterization of a Novel N-Vinylcaprolactam-Containing Acrylic Acid Terpolymer for Applications in Glass-Ionomer Dental Cements. Acta Biomaterialia, 5, 2101 2108. https://doi.org/10.1016/j.actbio.2009.02.015

[18] Xie, D., Culbertson, B.M. and Johnston, W.M. (1988) Improved Flexural Strength of $\mathrm{N}$-Vinylpyrrolidone Modified Acrylic Acid Copolymers for Glass-Ionomers. Journal of Macromolecular Science, Part A, 35, 1615-1629. https://doi.org/10.1080/10601329808000975

[19] Culbertson, B.M. (2001) Glass-Ionomer Dental Restoratives. Progress in Polymer Science, 26, 577-604. https://doi.org/10.1016/S0079-6700(01)00006-5

[20] Culbertson, B.M. (2006) New Polymeric Materials for Use in Glass-Ionomer Cements. Journal of Dentistry, 34, 556-565. https://doi.org/10.1016/j.jdent.2005.08.008

[21] Yamazaki, T., Brantley, W., Culbertson, B., Seghi, R. and Schricker, S. (2005) The Measure of Wear in N-Vinyl Pyrrolidinone (NVP) Modifed Glass-Ionomer Cements. Polymers for Advanced Technologies, 16, 113-116. https://doi.org/10.1002/pat.552

[22] Moshaverinia, A., Ansari, S., Movasaghi, Z., Billington, R.W., Darr, J.A. and Rehman, I.U. (2008) Modification of Conventional Glass-Ionomer Cements with $N$-Vinylpyrrolidone Containing Polyacids, Nano-Hydroxy and Fluoroapatite to Improve Mechanical Properties. Dental Materials, 24, 1381-1390. https://doi.org/10.1016/j.dental.2008.03.008

[23] Moshaverinia, A., Roohpour, N., Ansari, S., Moshaverinia, M., Schricker, S., Darr, J.A., et al. (2009) Effects of N-Vinylpyrrolidone (NVP) Containing Polyelectrolytes on Surface Properties of Conventional Glass-Ionomer Cements (GIC). Dental Materials, 25, 1240-1247. https://doi.org/10.1016/j.dental.2009.05.006

[24] Moshaverinia, A., Brantley, W.A., Chee, W.W.L., Rohpour, N., Rohpour, N., Ansari, S., et al. (2009) Measure of Microhardness, Fracture Toughness and Flexural Strength of N-Vinylcaprolactam (NVC)-Containing Glass-Ionomer Dental Cements. Dental Materials, 26, 1137-1143. https://doi.org/10.1016/j.dental.2010.08.002

[25] Wilson, A. and Prosser, H. (1982) Biocompatibility of the Glass Ionomer Cement. The Journal of the Dental Association of South Africa, 37, 872-879.

[26] Hehre, W.J., et.al. (2013) Spartan'14. Wavefunction, Inc., Irvine.

[27] Frisch, F.D., Trucks, M.J., Schlegel, G.W., Scuseria, H.B., Robb, G.E., Cheeseman, 
M.A., Scalmani, J.R., Barone, G., Mennucci, V., Petersson, B., Nakatsuji, G.A., Caricato, H., Li, M., Hratchian, X., Izmaylov, H.P., Bloino, A.F., Zheng, J., Sonnenberg, G., Hada, J.L., Ehara, M., Toyota, M., Fukuda, K. and Hasegaw, R. (2010) Gaussian 09, Revision B.01. Gaussian, Inc., Wallingford.

[28] Becke, A. (1993) Density-Functional Thermochemistry. III. The Role of Exact Exchange. Journal of Chemical Physics, 98, 5648-5652.

https://doi.org/10.1063/1.464913

[29] Zhao, Y. and Truhlar, D.G. (2008) The M06 Suite of Density Functionals for Main Group Thermochemistry, Thermochemical Kinetics, Noncovalent Interactions, Excited States, and Transition Elements: Two New Functionals and Systematic Testing of Four M06-Class Functionals and 12 Other Function. Theoretical Chemistry Accounts, 120, 215-241. https://doi.org/10.1007/s00214-007-0310-x

[30] Tomasi, J., Mennucci, B. and Cammi, R. (2005) Quantum Mechanical Continuum Solvation Models. Chemical Reviews, 105, 2999-3094.

https://doi.org/10.1021/cr9904009

[31] Ditchfield, R., Hehre, W. and Pople, J. (1971) Self-Consistent Molecular-Orbital Methods. IX. An Extended Gaussian-Type Basis for Molecular-Orbital Studies of Organic Molecules. Journal of Chemical Physics, 54, 724-728.

https://doi.org/10.1063/1.1674902

[32] McQuarrie, D.A. and Simon, J.D. (1999) Molecular Thermodynamics. University Science Books, Sausalito.

[33] Corey, R.B. and Pauling, L. (1953) Molecular Models of Amino Acids, Peptides, and Proteins. Review of Scientific Instruments, 24, 621-627.

https://doi.org/10.1063/1.1770803 